\section{Looking ahead to the greenhouse after ozone agreement reached}

London

LAST week's international agreement to protect the Earth's ozone layer from destruction by man-made chemicals (see Nature 329, 189; 1987) may spur policymakers to take on the complex issue of the greenhouse effect. Chlorofluorocarbons (CFCs), regulated by the new agreement because of links with ozone damage, are also 'greenhouse' gases, absorbing infrared radiation. The resultant warming effect is predicted to cause worldwide changes in temperature and weather patterns, as well as a substantial rise in sea level.

The United Nations Environment Programme (UNEP), which led international efforts to protect the ozone shield, is also studying ways of reducing emissions of greenhouse gases, and its director, Mostafa Tolba, has been asked by UNEP's governing council to come up with policy options by next year. The US Environmental Protection Agency is also studying the problem.

Controlling the greenhouse effect is far more complicated than implementing controls on CFCs. Other greenhouse gases are related to a complex web of energy policies, air pollution and other human activities.

The need to tackle the problem of the greenhouse effect was referred to at last week's Montreal meeting of signatories to the Vienna Convention for the Protection of the Ozone Layer, where 24 countries signed a protocol limiting the

production and consumption of CFCs and halons. The final agreement included compromises to lessen the effect on developing nations which want to continue to use CFCs as refrigerants - the lid on CFC production is 10 to 15 per cent higher than the cap on consumption to allow exports from producer countries.

Another compromise would allow the Soviet Union to complete two CFC plants now under construction, and to increase its per capita consumption. Even so, the Soviet Union did not sign the protocol, but said it may do so later. The final agreement calls for a 50 per cent cutback in consumption of fully halogenated CFCs by 1999 , with a 20 per cent cutback in 1994 and a freeze in 1990. Countries representing two-thirds of consumption must ratify the protocol before it comes into force.

The chemical industry is working on recovery and recycling processes for CFCs, but the race is also on to develop alternatives, a process that industry representatives say will take $5-10$ years. Some alternatives already exist. For refrigerators and automobile air conditioners, CFC 22, which is largely destroyed in the lower atmosphere because it contains hydrogen, could be substituted for ozone-damaging CFC 12 with some redesign of equipment. Fluorocarbon 134a contains no chlorine and therefore cannot destroy ozone, and is thought to be the most attractive long-term substitute.

Kathy Johnston

\title{
Hackers breach computer security across three continents
}

\section{Munich}

RESEARCH organizations throughout the world were busy last week playing down the importance of a penetration of their computer systems by an anonymous West German group. A total of 135 computer systems in Europe, the United States and Asia, including those of the US National Aeronautics and Space Administration (NASA), CERN, ESA, the German Aerospace Research Establishment and the European Molecular Biology Laboratory (EMBL) were penetrated through the computer network SPAN (Space Physics Analysis Network).

Chris Sander of EMBL says there is "no visible damage" to the EMBL computer system. EMBL already guards its research computers and may switch its administrative accounts onto a new system, a move it "would have done anyway", says Sander.

NASA says that no confidential data were compromised, despite the claim by the intruders that they gatherer 200 pages of sensitive documentation before the alarm went out about the breach in August. Several NASA drawings (of the space shuttle, for example) were shown on West German television on 15 September and cited as proof of the break-in.

The computer 'hackers', speaking through the Chaos computer club of Hamburg, West Germany (which takes no responsibility for the break-ins), said they intended no harm and that the public announcement of their success was meant as a "warning" to the computer manufacturers and system operators that their machines are not secure. The hackers first accidentally entered SPAN in the spring of this year by falling through a 'loophole' in the software. They left a 'Trojan horse' inside the system, a program enabling them to re-enter at will.

The presence of the intruders was

\section{Vatican astronomers are visited by Pope}

Phoenix, Arizona

DURING his recent US tour, Pope John Paul II took a few minutes out from his busy schedule for a lesson in telescope making. While in Phoenix, Arizona, the pontiff spent 15 minutes in a private session with astronomers from the University of Arizona, the Vatican Observatory and the National Optical Astronomy Observatories, arranged by George Coyne, director of the Vatican Observatory and adjunct professor at the university.

Since 1981, Vatican astronomers have spent about 9 months a year studying stars from the university's Steward Observatory in Tucson. The group hopes soon to have its own 1.8-metre Vatican Advanced

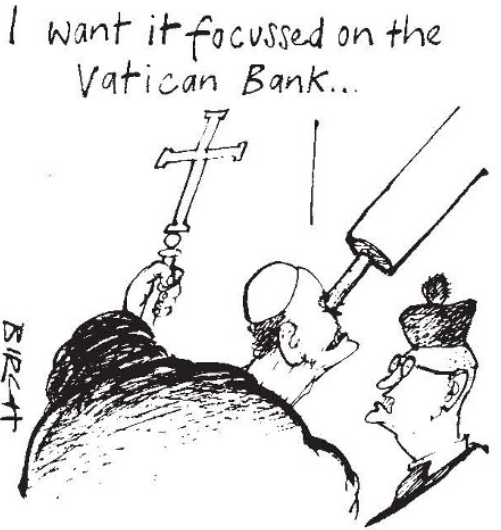

Technology Telescope based in Arizona. This telescope will be the first produced by spin-cast technology, a process for making honeycomb mirrors with very short focal lengths. It was developed by J. Roger Angel at the University of Arizona.

The Pope is not an astronomy buff, said Boyle, but is "very seriously interested in science and religion and in the relationship between science and religion."

The Vatican Observatory is the Vatican's only formal research institution in the physical sciences. It was set up in 1891 by Pope Leo XIII, at Castel Gandolfo, the papal summer residence near Rome. Light pollution prompted Vatican astronomers to seek darker skies in Arizona.

Elizabeth Pennisi

discovered in early August by a systems manager at EMBL, who alerted other users. No criminal proceedings are expected. Legal provisions do exist but there are few precedents, and "evidence would be extremely hard to come by", said Steffen Wernery of Chaos.

Changing operating systems and installing more security measures in SPAN might provide temporary relief to the legal users. But all agree that security problems are here to stay. Said Wernery, "The hackers always try to stay at the cutting edge." 